\title{
Synthesis and characterisation of zinc oxide nanoparticles using terpenoid fractions of Andrographis paniculata leaves
}

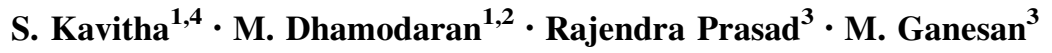

Received: 23 May 2016/Accepted: 3 April 2017/Published online: 19 April 2017

(C) The Author(s) 2017. This article is an open access publication

\begin{abstract}
Zinc oxide ( $\mathrm{ZnO})$ nanoparticles have been widely employed for various pharmacological applications. Several approaches were tried to synthesize $\mathrm{ZnO}$ nanoparticles. In this study, $\mathrm{ZnO}$ nanoparticles were biosynthesized using terpenoid (TAP) fractions isolated from Andrographis paniculata leaves. Subsequently, the $\mathrm{ZnNO}_{3}(0.1 \mathrm{~N})$ is treated with the isolated TAP fractions to biosynthesize zinc oxide nanoparticles (Zn-TAP NPs). This nanoparticle preparation has been confirmed by the colour change from green to cloudy-white and the peak at $300 \mathrm{~nm}$ by UV-Visible spectra. FTIR analysis of Zn-TAP NPs showed the presence of functional group (i.e.) $\mathrm{C}=\mathrm{O}$ which has further been confirmed by $\mathrm{H}^{1}$-NMR studies. From SEM and XRD analysis, it has been found that the hexagonal nanorod particle is $20.23 \mathrm{~nm}$ in size and $+17.6 \mathrm{mV}$ of zeta potential. Hence, it can be easily absorbed by negatively charged cellular membrane to contribute for efficient intracellular distribution. Therefore, it is suggested that the synthesised Zn-TAP NPs are more suitable in drug delivery processes.
\end{abstract}

$\square$ S. Kavitha

coolkavesh@gmail.com

M. Dhamodaran

dhamu_762003@yahoo.co.in

1 Department of Chemistry (R\&DC), Bharathiar University, Coimbatore, Tamil Nadu, India

2 Department of Chemistry, Perunthalaivar Kamarajar Institute of Engineering and Technology (PKIET) (Government of Puducherry Institution), Karaikal, Puducherry U.T., India

3 Department of Biochemistry and Biotechnology, Annamalai University, Chidambaram, Tamil Nadu, India

4 A.V.C. Polytechnic College, Mannampandal, Mayiladuthurai, Nagai (DT), Tamil Nadu 609305, India
Keywords Terpenoids - Nanoparticles $\cdot$ Andrographis paniculata $\cdot \mathrm{ZnNO}_{3} \cdot \mathrm{Zinc}$ oxide nanoparticles

\section{Introduction}

Nanotechnology is an upcoming field of science which has its impact in various fields such as energy, environment, electronics, etc. The widespread practical applications of metal nanoparticles (particles less than $100 \mathrm{~nm}$ ) are attributed to their unique properties [1]. Different physical and chemical processes are widely used to synthesize metal nanoparticles [2]. However, these production methods are usually expensive, labor-intensive, and are potentially hazardous to the environment and living organisms [3]. Thus, there is an obvious need for an alternative, costeffective and at the same time, safe and environmentally sound method of nanoparticles production [4]. During the past decades, it has been demonstrated that many biological systems, including plants and bacteria [5] and fungi [6] can transform inorganic metal ions into metal nanoparticles via the reductive capacities of the proteins and metabolites present in these organisms.

The ability of plant extracts to reduce metal ions has been known since the early 1900s, although the nature of the reducing agents involved was not well understood. Because of its simplicity, the use of live plants or whole plant extracts and plant tissue for reducing metal salts to nanoparticles has attracted considerable attention within the last 30-years [7]. Plant extracts act both as reducing and stabilizing agents in the synthesis of nanoparticles [8]. The source of the plant extract is known to influence the characteristics of the nanoparticles [9]. This is because different extracts contain different concentrations and combinations of organic reducing agents [10]. Typically, a 
plant extract-mediated bioreduction involves mixing aqueous extract with an aqueous solution of the relevant metal salt. The reaction occurs at room temperature and is generally completed within a few minutes. Due to the number of different chemicals involved, the bioreduction process is relatively complex.

Nanoparticles have gained importance due to the awareness in biological processes. The chemicals present in the plant with anti-oxidant property are the basis for the preparation of zinc oxide nanoparticle. It has become a necessity to develop nanoparticles which in turn can be targeted on different applications [11]. Nanoparticles of zinc oxide are under intensive study for their applications in the field of optical devices, catalysis, biotechnology, DNA labeling, drugs and medical and chemical sensors. Nanosized zinc oxide has found various applications (sunscreen coatings and paints) due to its high absorption in UV $[12,13]$.

Currently, researchers are focusing on the synthesis of nanoparticles using green methods. Synthesis of nanoparticles using green methods increases the biological effectiveness. Bio-nanoparticles have greater catalytic activity due to the increase in the surface area. The possibility of using plant materials as nano-precursors has also been studied. The plant species A. paniculata, commonly known as Nilavembu in India, belongs to the Acanthaceae family. It is found in a large extent throughout South China, Asian countries and Sri Lanka. It is also known as "King of bitters" $[14,15]$. Despite its bitter taste, this species possesses pharmacological properties, i.e. antimicrobial, antioxidant, antiinflammatory, antiparasitic, antihyperglycemic, hypoglycemic and antiallergic [16]. Andrographis paniculata reduces oxidation level due to its steroidal characteristics and destroys infected somatic cells. It contains diterpenes, lactones and flavonoids. The leaf and stem extracts have glycosides, flavonoids, gums, steroids, terpenoids, tannins, saponins and phenolic compounds [17]. Compared to its other parts, the leaf, which has multiple clinical applications, has huge amounts of terpenoid (TAP) (2.39\%) which accounts for the bitter taste in leaves. This reason has been an impetus to isolate the medically most active and major compound TAP from the leaf. Therefore, in this study TAPs were isolated from A. paniculata and used to prepare $\mathrm{ZnO}$ nanoparticles for possible pharmacological applications.

\section{Materials and methods}

\section{Collection of plant, chemical materials and cancer cell lines}

The plant A. paniculata was collected from the campus of A.V.C. Arts and Science College, Mayiladuthurai. The AR grade chemicals and solvents like zinc nitrate tetrahydrate, sodium hydroxide, ethanol, chloroform, silica gel and $\mathrm{CDCl}_{3}$ were procured from Merck Chemicals, Pune, India.

\section{Extract preparation}

The collected A. paniculata leaves were cleaned with tap water then rinsed with distilled water, dried, cut into small parts and ground into fine powder. It was further stored at $37^{\circ} \mathrm{C}$.

\section{Preparation of terpenoid fractions from $A$. paniculata}

The terpenoid fractions were separated by column chromatography. In this method, $25 \mathrm{~g}$ silica gel powder was filled in column apparatus and mixed with ethanol up to slurry formation. Then the solvent was completely eluted, and added $50 \%$ mixture $\left(65 \mathrm{~mL} \mathrm{CHCl}_{3}\right.$ and $1 \mathrm{~mL}$ methanol). It was followed by adding $10 \mathrm{~mL}$ ethanolic sample. Finally, the remaining mixture was added. The solvent was eluted. Within $12 \mathrm{~h}$ terpenoid was collected in test tubes.

\section{Phytochemical test for terpenoid (TAP) fractions from A. paniculata}

\section{Confirmative test for terpenoids}

Salkowskis test TAP was mixed with a few drops of chloroform and concentrated sulphuric acid. The formation of yellow colour indicates the presence of terpenoids.

The extract was treated with $1 \mathrm{~mL}$ of $\mathrm{CHCl}_{3}, 1 \mathrm{~mL} \mathrm{CH}_{3}$ $\mathrm{COOH}$ and few drops of concentrated sulphuric acid. Appearance of brown ring indicates the presence of terpenoids.

\section{Synthesis of zinc oxide nanoparticles (Zn-NPS)}

Zinc oxide nanoparticles were prepared by green synthesis (co-precipitation) method. $0.1 \mathrm{~N}$ aqueous solution of zinc

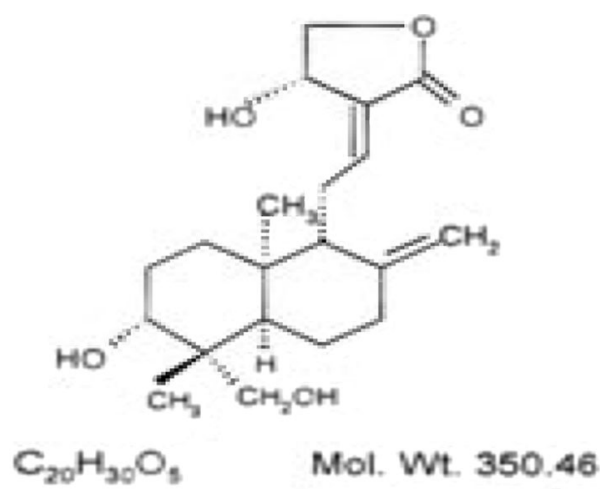

Fig. 1 TAP mediated Zn-TAP NPs synthesis 
Fig. 2 Schematic diagram of Zn-TAP NPs synthesis

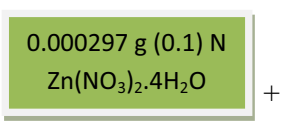

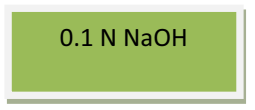

$50 \mathrm{~mL}$ distilled

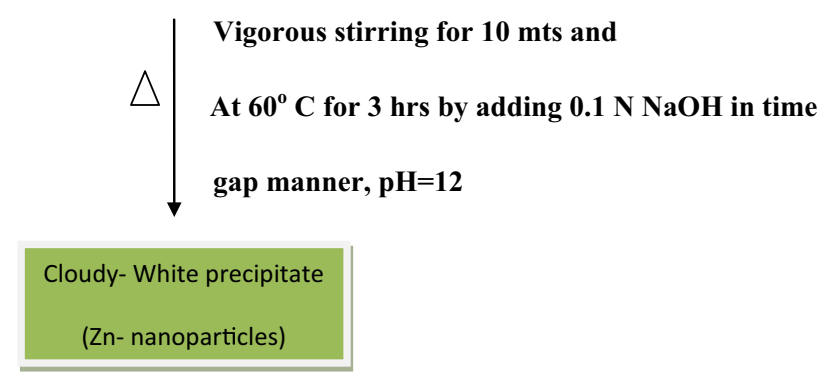

nitrate tetrahydrate $\left(\mathrm{Zn}\left(\mathrm{NO}_{3}\right)_{2} \cdot 4 \mathrm{H}_{2} \mathrm{O}\right)$ was added to $50 \mathrm{~mL}$ distilled water by continuous shaking. Later $0.1 \mathrm{~N} \mathrm{NaOH}$ was added in $10 \mathrm{~m}$ gap for an hour. Following that, the time gap was increased for adding the $\mathrm{NaOH}$. The procedure was repeated for $2 \mathrm{~h}$. The obtained white solution was stirred for $2 \mathrm{~h}$ at $\mathrm{pH} 12$. The product was washed with distilled water and ethanol to get the final product. It is then dried overnight. The whole mode of proposed method for the synthesis of Zn-NPs mediated by the aqueous extract was illustrated.

\section{Characterisation of terpenoid zinc oxide nanoparticles (Zn-TAP NPs) from A. paniculata}

\section{Particle size and zeta potential measurements}

DLS and zeta potential were based on the direction and velocity of particles under the influence of known electric field. Malvern Zetasizer ZS (Malvern Instruments, Malvern, UK) instrument was used to measure particle size, size distribution and zeta potential of Zn-TAP NPs. To suit the above situation a homogenous suspension was created using the lyophilized nanoparticles in double distilled water and repeated thrice.

\section{Scanning electron microscopy (SEM)}

The samples were placed on a carbon plated platinum strip. Splash drops were wiped off. It was dried in mercury lamp for $5 \mathrm{~m}$ and examined under SEM (using JEOL JSM-6610 LV SEM machine).

\section{$X$-ray diffraction $(X R D)$ analysis}

At $\lambda=0.1546 \mathrm{~nm}$, running at $40 \mathrm{kV}$ and $30 \mathrm{~mA}$ in X-ray diffractometer (X'Pert PRO-PANalytical Philips). Zinc oxide nanoparticles were recorded in the region from $10^{\circ}$ to $80^{\circ}$ at a scan speed of $2 \theta$ per minute.
UV spectroscopic analysis

The Zn-TAP NPs were dissolved in distilled water $(1 \mathrm{mg} /$ $\mathrm{mL}$ ) and scanned in a Perkin Elmer Lambda $25 \mathrm{UV}-\mathrm{Vis}$ spectrometer at $25^{\circ} \mathrm{C}$ in the range of $250-650 \mathrm{~nm}$. The UV spectrum was repeated three times.

Fourier transform infrared spectroscopy (FTIR) analysis

Zn-TAP NPs and potassium bromide 10 and $100 \mathrm{mg}$ were respectively mixed to form a salt plate. Spectra between 4000 and $400 \mathrm{~cm}^{-1}$ were noted in a Bio-Rad FTIR-40 (USA).

Proton nuclear magnetic resonance spectroscopy $\left({ }^{1} \mathrm{H}-\mathrm{NMR}\right)$ analysis

An approximately $30 \mathrm{mg}$ of Zn-TAP NPs was made soluble in $0.5 \mathrm{~mL} \mathrm{CDCl} 3(99.9 \%)$. At $27{ }^{\circ} \mathrm{C}{ }^{1} \mathrm{H}$-NMR spectra were recorded by Luo and Fan method (2011).

\section{Results}

\section{Green synthesis of zinc oxide nanoparticles}

The biosynthesised Zn-TAP NPs were isolated (Fig. 1) using $0.1 \mathrm{~N}$ Zinc nitrate with $\mathrm{NaOH}$ of co-precipitation method at pH 12 (Fig. 2).

\section{Characterisation of Zn-TAP NPs from A. paniculata}

Particle size and zeta potential of Zn-TAP NPs

Figure 3a shows the size distribution of the Zn-TAP NPs in aqueous medium. It was measured by DLS. The average particle size was $20.23 \mathrm{~nm}$. Figure $3 \mathrm{~b}$ reveals that the zeta potential of synthesized $\mathrm{ZnO}$ nanoparticles was $17.6 \mathrm{mV}$. 
a

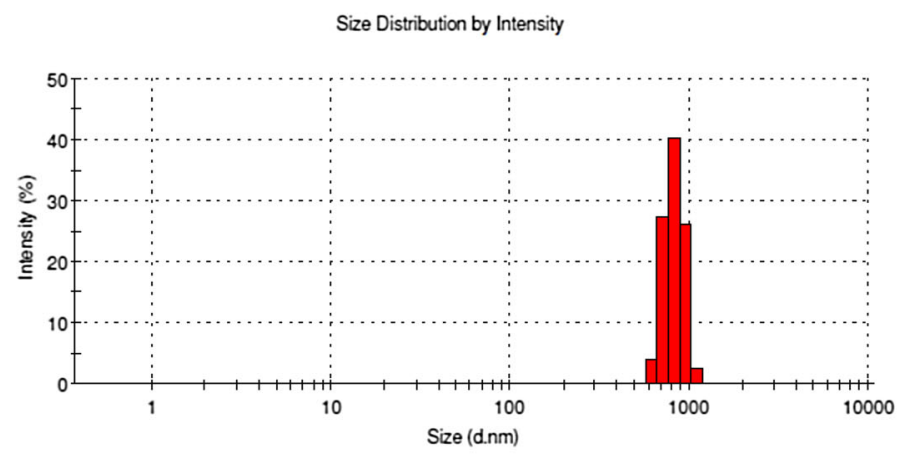

Record 4: TAP-1Z 1 b

Results

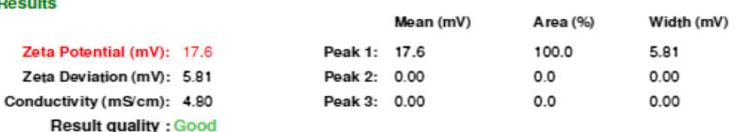

Zeta Potertial Distribuson

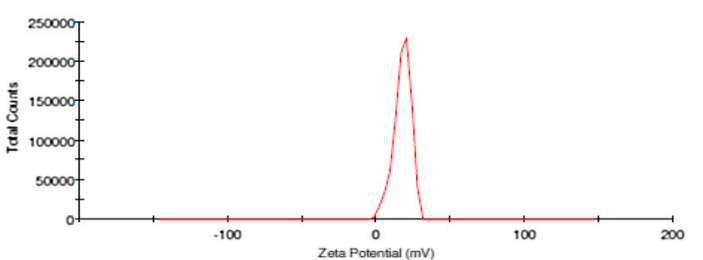

E Record 17:TAP-1Z-Zeta1

C

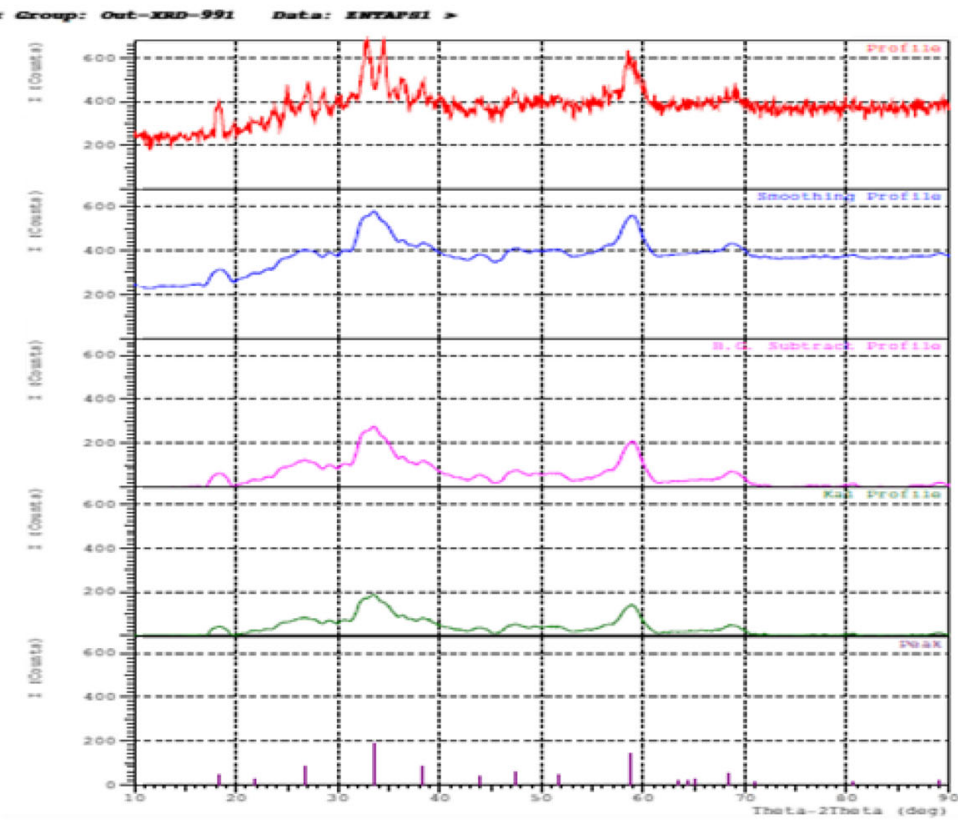

d SEM for Zn- NP's from A.Paniculata leaves
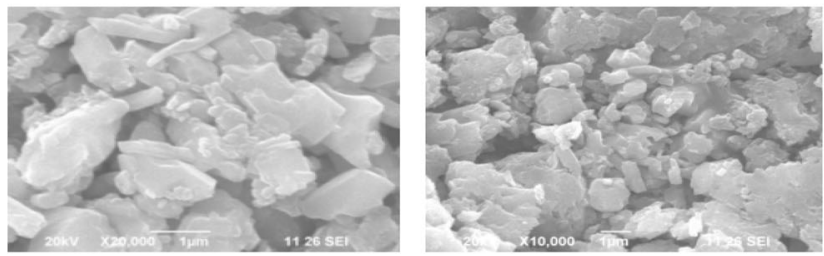

Fig. 3 a Particle size for Zn-TAP NPs from A. paniculata leaves. b Zeta potential of Zn-TAP NPs. c XRD images of Zn-TAP NPs. d SEM for Zn-TAP NPs

\section{XRD analysis of Zn-TAP NPs}

X-ray diffraction was used to confirm the crystalline nature of the particles by no discernible peak in the low range $\left(2 \theta=1^{\circ}-10^{\circ}\right)$. Figure $3 \mathrm{c}$ shows a representative XRD pattern of the $\mathrm{ZnO}$ nanoparticles synthesized by the $A$. paniculata extract after the complete reduction of $\mathrm{Zn}^{2+}$ to $\mathrm{Zn}^{0}$. A number of Bragg reflections were present which can be indexed on the basis of the hexagonal Wurtzite structure of $\mathrm{ZnO}$. The diffraction peaks at (100), (002), (101), (102) and (110) were obtained with those reported values of standard card (JCPDS no: 36-1451) [18]. 

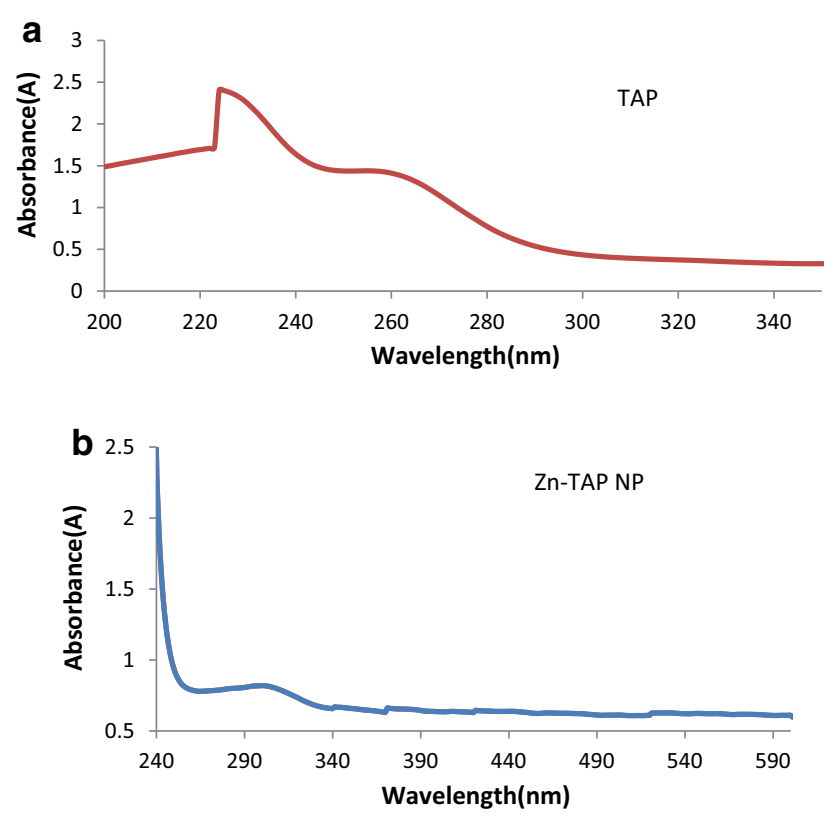

Fig. 4 a UV absorption of TAP isolated from A. paniculata leaves. b UV absorption of Zn-TAP NPs from A. paniculata leaves

From the XRD peaks, to estimate the average particle size was calculated by using Scherrer's equation as $22.23 \mathrm{~nm}$. These values are merely similar to DLS size.

\section{SEM analysis of Zn-TAP NPs}

The synthesised Zn-TAP NPs morphology was examined by SEM in JEOL JSM-6610 LV instrument. When the nanoparticle was placed on carbon coated platinum grid, after completion of reaction, it showed a hexagonal shape as indicated in Fig. 3d.

\section{UV spectroscopy studies}

The formation of zinc oxide nanoparticles might be due to reduction of $\mathrm{Zn}^{2+}$ to $\mathrm{Zn}^{0}$ by terpenoids present in the leaf of A. paniculata. The colour transformation of A. paniculata extract treated with zinc nitrate might be due to vibrations in surface plasmon resonance of zinc [19]. Because it has free - -electrons $(\mathrm{C}=\mathrm{O})$. The broad band at $300 \mathrm{~nm}$ indicates the reduction of $\mathrm{Zn}^{2+}$ ions which further confirmed the formation of zinc oxide nanoparticles in Fig. $4 \mathrm{~b}$. Whereas, the isolated active compound TAP has no absorbance change in the range of $280-350 \mathrm{~nm}$ (Fig. 4a).

\section{Fourier transform infrared spectroscopy (FTIR) studies}

The FTIR spectroscopy measurements were studied to identify the possible bio-molecules responsible for reducing the ZNO-NPs synthesised through TAP. The IR spectra of TAP (Fig. 5a) exhibit strong absorption band at $3334.71 \mathrm{~cm}^{-1}$ for $\mathrm{O}-\mathrm{H}$ stretching vibration. The $\mathrm{C}-\mathrm{O}$ axial stretching band appears at $1656.36 \mathrm{~cm}^{-1}$. The peak at $2852.85 \mathrm{~cm}^{-1}$ corresponds to $\mathrm{C}-\mathrm{H}$ stretching vibration. Another report was assigned that the peak at $1656.36 \mathrm{~cm}^{-1}$ is due to $-\mathrm{C}=\mathrm{C}-$ aromatic stretching.

The peak was observed for Zn-TAP NPs between 513 and $466 \mathrm{~cm}^{-1}$ (Fig. 5b). The bands appeared between 600 and $400 \mathrm{~cm}^{-1}$ which may be assigned to the metal oxide or metal chloride $[20,21]$, which confirm the formation of $\mathrm{ZnO} \mathrm{NPs}$ at $466.77 \mathrm{~cm}^{-1}$. The absorbance at $3479.58 \mathrm{~cm}^{-1}$ indicates the $\mathrm{O}-\mathrm{H}$ stretching vibration in hydroxyl functional group of alcohols and phenol compounds of ZnO NPs. The absorption peak at $2929.87 \mathrm{~cm}^{-1}$ corresponds to $-\mathrm{CH}$ stretching and $2767.85 \mathrm{~cm}^{-1}$ for aldehydic $-\mathrm{CH}$ vibration mode. $1764.87 \mathrm{~cm}^{-1}$ is assigned
Fig. 5 a and $\mathbf{b}$ FTIR of TAP and Zn-TAP NPs from $A$. paniculata leaves

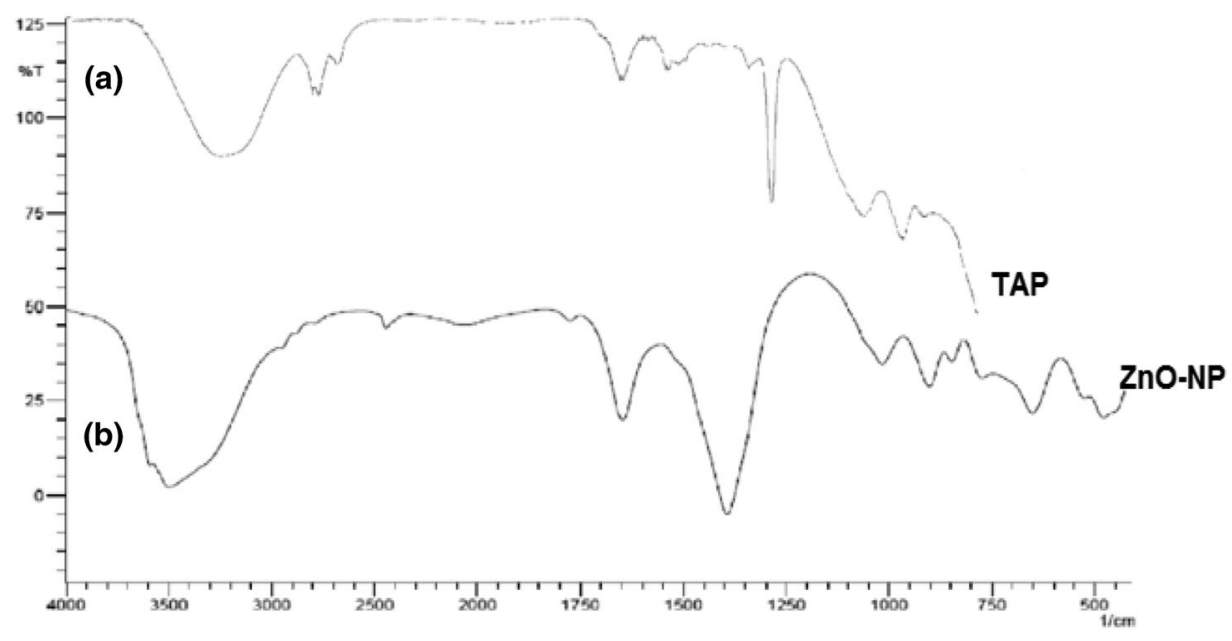


Fig. $6 \mathrm{H}^{1} \mathrm{NMR}$ for $\mathrm{Zn}-\mathrm{TAP}$

NPs from A. paniculata leaves

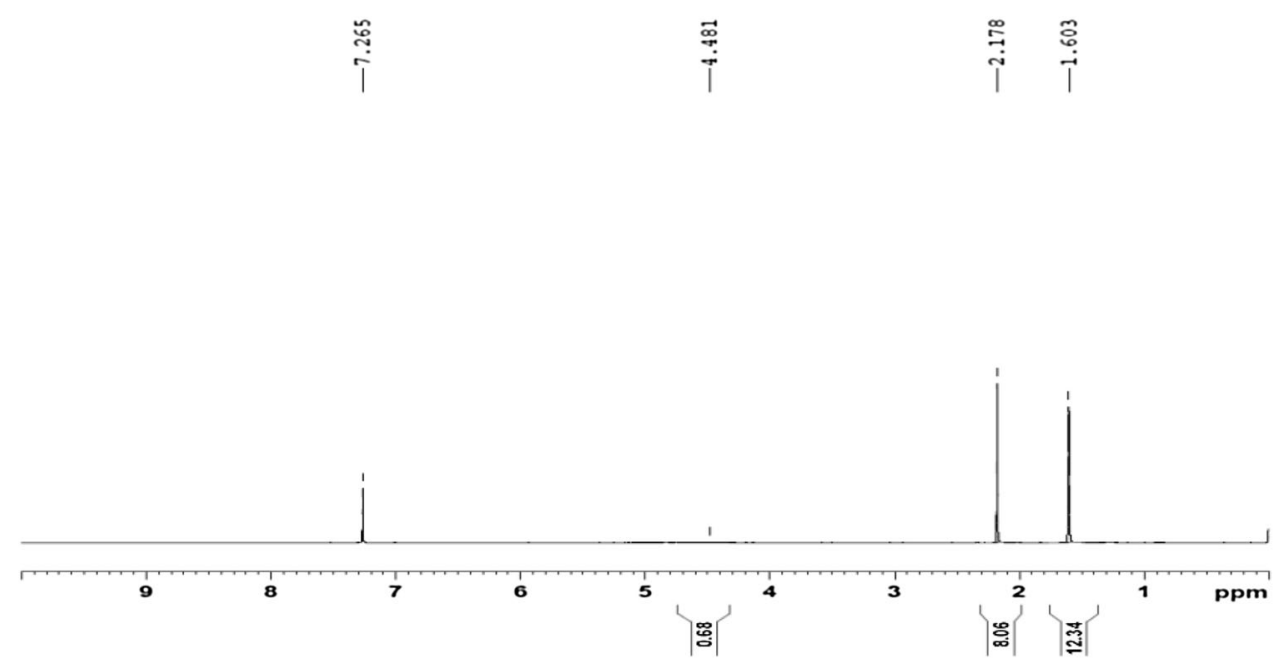

to aldehydic carbonyl $(-\mathrm{CH}=\mathrm{O})$ group. Some other bands at $1637.56,1382.96,1004.91$ and $640.37 \mathrm{~cm}^{-1}$ were also seen which correspond to aromatic $-\mathrm{C}=\mathrm{C}-, \mathrm{C}-\mathrm{H}$ group, $\mathrm{CH}_{2}$ group and mono substituted ring which indicate that the TAP of $A$. paniculata reduced by $\mathrm{ZnO}$ NPs might be surrounded by aromatic ring polyphenol [22]. The band at $1637.56 \mathrm{~cm}^{-1}$ remained in $\mathrm{ZnO}$ NPs and this is due to groups with a benzene ring. Another report has assigned that the peak at $1637.56 \mathrm{~cm}^{-1}$ is due to $-\mathrm{C}=\mathrm{C}-$ aromatic stretching [23].

Proton nuclear magnetic resonance spectroscopy $\left({ }^{1} \mathrm{H}\right.$ NMR) studies

In $\mathrm{CDCl}_{3}$ solvent, $\mathrm{H}^{1}$-NMR spectrum (Fig. 6) showed the $3 \mathrm{H}, \mathrm{s},>\mathrm{C}=\mathrm{CH}_{2}$ group at $\delta 1.603$. The peak at $\delta 2.178$ assigned to phenyl group stretching. The absorption peak at $\delta 4.481$ corresponds to $\mathrm{H}_{3} \mathrm{C}-\mathrm{O}-\mathrm{CO}-\mathrm{CH} 3$ stretching vibration. The band appears at $\delta 7.265$ for aromatic compound. Another report was assigned that the peak at $\delta$ 2.178 and $\delta 4.481$ corresponds to aliphatic $-\mathrm{OH}$ and aromatic $-\mathrm{OH}$ group respectively.

\section{Conclusion}

TAP could be adsorbed on the surface of nanoparticles possibly by interaction through carbonyl groups or electrons. The formation of $\mathrm{ZnO}$ NPs was confirmed by colour changes and was characterised by UV-Visible spectrophotometer. The broad band was observed at $300 \mathrm{~nm}$. It was proved by IR spectra band at $466.77 \mathrm{~cm}^{-1}$. The presence of functional groups in $\mathrm{ZnO}$ NPs was also confirmed by IR and $\mathrm{H}^{1}$-NMR studies. The SEM analysis shows hexagonal shape particles with $20.23 \mathrm{~nm}$ size which was merely close to Scherrer's value (i.e.) $22.23 \mathrm{~nm}$. Zn-
TAP NPs has positive zeta potential value $17.6 \mathrm{mV}$. Hence, it was proposed that it can be easily absorbed by negatively charged cellular membrane and then contributes to efficient intracellular distribution of drug.

Open Access This article is distributed under the terms of the Creative Commons Attribution 4.0 International License (http://crea tivecommons.org/licenses/by/4.0/), which permits unrestricted use, distribution, and reproduction in any medium, provided you give appropriate credit to the original author(s) and the source, provide a link to the Creative Commons license, and indicate if changes were made.

\section{References}

1. Daniel, M.C., Astruc, D.: Gold nanoparticles: assembly, supramolecular chemistry, quantum-size-related properties, and applications toward biology, catalysis, and nanotechnology. Chem. Rev. 104(1), 293-346 (2004)

2. Kundu, S., Maheshwari, V., Niu, S., Saraf, R.F.: Polyelectrolyte mediated scalable synthesis of highly stable silver nanocubes in less than a minute using microwave irradiation. Nanotechnology 19(6), 065604 (2008)

3. Gan, P.P., Ng, S.H., Huang, Y., Li, S.F.: Green synthesis of gold nanoparticles using palm oil mill effluent (POME): a low-cost and eco-friendly viable approach. Bioresour. Technol. 113, 132-135 (2012)

4. Raveendran, P., Fu, J., Wallen, S.L.: Completely "green" synthesis and stabilization of metal nanoparticles. J. Am. Chem. Soc. 125(46), 13940-13941 (2003)

5. Kalishwaralal, K., Deepak, V., Pandian, S.R.K., Kottaisamy, M., BarathmaniKanth, S., Kartikeyan, B., Gurunathan, S.: Biosynthesis of silver and gold nanoparticles using Brevibacterium casei. Colloids Surf. B Biointerfaces 77(2), 257-262 (2010)

6. Kitching, M., Ramani, M., Marsili, E.: Fungal biosynthesis of gold nanoparticles: mechanism and scale up. Microb. Biotechnol. 8(6), 904-917 (2015). doi:10.1111/1751-7915.12151

7. Ankamwar, B.: Biosynthesis of gold nanoparticles (green-gold) using leaf extract of Terminalia catappa. Eur. J. Chem. 7, 1334-1339 (2010)

8. Kumar, V., Yadav, S.C., Yadav, S.K.: Syzygium cumini leaf and seed extract mediated biosynthesis of silver nanoparticles and 
their characterization. J. Chem. Technol. Biotechnol. 85, 1301-1309 (2010)

9. Kumar, V., Yadav, S.K.: Plant-mediated synthesis of silver and gold nanoparticles and their applications. J. Chem. Technol. Biotechnol. 84, 151-157 (2009)

10. Mukunthan, K., Balaji, S.: Cashew apple juice (Anacardium occidentale L.) speeds up the synthesis of silver nanoparticles. Int. J. Green. Nanotechnol. 4, 71-79 (2012)

11. Gnanasangeetha, D., Sarala Thambavani, D., et al.: One pot synthesis of zinc oxide nanoparticles via chemical and green method. Res. J. Mater. Sci. Int. Sci. Congr. Assoc. 1(7), 1-8 (2013)

12. Gnanasangeetha, D., Sarala Thambavani, D., et al.: Facile and eco-friendly method for the synthesis of zinc oxide nanoparticles using Azadirachta and Emblica. Int. J. Pharm. Sci. Res. 5(7), 2866-2873 (2014)

13. Fan, Z., Lu, J.G., et al.: Zinc oxide nanostructures: synthesis and properties. J. Nanosci. Nanotechnol. 5(10):1561-1573 (2005)

14. Hosamani, P.A., Lakshman, H.C., Sandeepkumar, K., et al.: Antimicrobial activity of leaf extract of Andrographis paniculata wall. Sci. Res. Rep. 1(2), 92-95 (2011)

15. Sivarajan, V.V., Balachandran, I., et al.: Ayurvedic drugs and their plant sources. pp. 570-95. Oxford and IBH Publishing Co. Pvt. Ltd., New Delhi (1994) http://jsrr.in Hosamani et al. ISSN: 2249- int)

16. Sule, A., Ahmed, Q.U., Samah, O.A., et al.: Screening for antibacterial activity of the treatment of skin infections. Ethnobot. Leafl. 14, 445-456 (2010)
17. Goodman, S.L., Gilman, A.: The pharmacological basis of therapeutics, 9th edn, pp. 959-975. Macmillan Publishing Co Inc, New York (2000)

18. Kohler, G.: An continuous cultures of fused cells secreting antibody of predefined specificity. Nature 256, 495-497 (1975)

19. Gao, Q.Q., Yu, Q.X., Yuan, K., et al.: Influence of annealing atmosphere on room temperature ferromagnetism of Mn-doped $\mathrm{ZnO}$ nanoparticles. Appl. Surf. Sci. 264, 7-10 (2013)

20. Nakamoto, K.: Infrared and Raman spectra of inorganic and coordination compound, 4th edn. Willey, New York (1986)

21. Vinod, K., Pandey, O.P., Soumitra, K.: Synthesis and physicochemical and biological studies on ruthenium (III) complexes with Schiff bases derived from aminocarboxylic acids. Transit. Met. Chem. 12, 509-515 (1987)

22. Rajasekar, R., Priyadharshini, S., Rajarajeshwari, T., et al.: Bioinspired synthesis of silver nanoparticles using Andrographis paniculata whole plant extract and their anti-microbial activity over pathogenic microbes. Int. J. Res. Biomed. Biotechnol. 3(3), 47-52 (2013)

23. Raghunandan, D., Bedre, M.D., Basavaraja, S., et al.: Rapid biosynthesis of irregular shaped gold nanoparticles from macerated aqueous extracellular dried clove buds (Syzygium aromaticum) solution. Colloids Surf. B Biointerfaces 79, 235-240 (2011) 